\title{
Security and Development in Developing Countries
}

\author{
Minh Quang Dao \\ Economics Department, Eastern Illinois University, Charleston, USA \\ E-mail:mqdao@eiu.edu \\ Received August 19, 2011; revised September 25, 2011; accepted October 10, 2011
}

\begin{abstract}
This paper examines the impact of security on economic development in developing countries. Based on data from the World Bank, we use a sample of thirty-eight developing economies and find that security does affect development in these countries. We observe that the coefficient estimates of two explanatory variables do not have their anticipated sign due possibly to the slight degree of multicollinearity between them. Regression results show that over three-quarters of cross-developing country variations in purchasing power parity per capita gross national income can be explained by its linear dependency on the number of intentional homicides, the number of refugees hosted by a country, military expenditures as a percentage of GDP, the adult literacy rate, the agricultural value added per worker, the share of manufactures in total merchandise exports, net foreign direct investment, net official development assistance, the share of agricultural land in the total land area, the share of public health expenditures in total health expenditures, and the share of youths 15 to 34 years old in the total population. Statistical results of such empirical examination will assist governments in developing countries identify security and other issues that need to be effectively dealt with in order to stimulate economic development.
\end{abstract}

Keywords: Security, Purchasing Power Parity per Capita GNI, Adult Literacy Rate, Intentional Homicides, Developing Countries, Refugees by Country of Asylum, Military Expenditures.

\section{Introduction}

The issue of the effect of security on economic development has not received sufficient attention in the development economics literature. Murdoch and Sandler quantify the impact of civil wars on economic growth in the home and neighboring countries [1]. They find that in general distance measures provide better measures of the diffusion of the negative economic impacts of civil wars on other countries. They also find that both the duration and the timing of civil wars have an economic effect. On the other hand, Bayer and Rupert examine the effect of civil war in one country on the total bilateral trade between the affected country and its trading partners [2]. Using data for 120 countries between 1950 and 1992 they find that civil wars reduce bilateral trade among countries by one-third. Furthermore, these effects also are felt in neighboring states as well. For each neighbor in conflict, a country on its path to development such as Tanzania, experiences an estimated loss of 0.7 percent of GDP.A more recent study of 18 Western European countries by Gaibulloev and Sandler reveals that each additional transnational terrorist incident decreases their economic growth by 0.4 of a percentage point each year [3]. De
Groot analyzes the influence of conflict on the economies of neighboring countries and concludes that conflict actually has two opposing effects [4]. On the one hand, directly contiguous countries and conflict countries themselves suffer from the negative consequences of proximate conflict. However, there is also a positive spillover effect on non-contiguous countries and this effect is larger for countries that are closer to the conflict country. De Groot cautions that his results for the most part hold for the most violent type of conflict. The 2011 World Development Report offers some advices on how to move beyond conflict and fragility and secure development. One of them is investing in citizen security, justice, and jobs in order to reduce violence. Thus, the current study empirically examines the effect of security on economic development. Using data from the World Bank for a sample of thirty-eight ${ }^{1}$ developing economies for

\footnotetext{
${ }^{1}$ The sample consists of the following countries: Armenia, Bangladesh, Bolivia, Burkina Faso, Cameroon, China, Côte d’Ivoire, Ecuador, Egypt, El Salvador, Ethiopia, Ghana, Georgia, Guatemala, India, Indonesia, Jordan, Kenya, Moldova, Mongolia, Morocco, Nepal, Nicaragua, Pakistan, Paraguay, Philippines, Rwanda, Senegal, Sri Lanka, Syrian Arab Republic, Swaziland, Tanzania, Thailand, Tunisia, Uganda, Ukraine, Vietnam, and Zambia.
} 
the period from 2000 to 2009, we find that neither the proportion of a country's population that is employed nor the percentage of male youth population 15 to 34 years old out of the total population is statistically significant in explaining economic development in these countries. We are able to show that over three-quarters of crossdeveloping country variations in purchasing power parity per capita gross national income can be explained by its linear dependency on the number of intentional homicides, the number of refugees hosted by a country, military expenditures as a percentage of GDP, the adult literacy rate, the agricultural value added per worker, the share of manufactures in total merchandise exports, net foreign direct investment, net official development assistance, the share of agricultural land in the total land area, the share of public health expenditures in total health expenditures, and the share of youths 15 to 34 years old in the total population. Statistical results of such empirical examination will help governments in developing countries identify areas that need special attention in order to foster economic development. This paper is organized as follows. In the next section, the formulation of a statistical model to be estimated is discussed. Theoretical underpinnings for the inclusion of explanatory variables are presented in this section. Statistical results are reported in the subsequent section. A final section gives concluding remarks as well as policy recommendations.

\section{The Statistical Model}

If we assume that various exogenous factors linearly affect the level of per capita GDP in a developing country, we can state the following statistical model:

$$
\begin{aligned}
& \text { PPPGNI }=\beta_{0}+\beta_{1} \text { Death }+\beta_{2} \text { Homicides }
\end{aligned}
$$

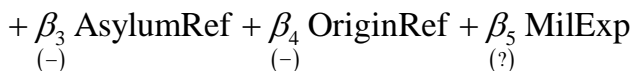

$$
\begin{aligned}
& +\beta_{6} \text { YouthMale }+\beta_{7} \text { Literacy }+\beta_{8} \text { AgValue } \\
& (?) \quad(+) \quad(+) \\
& +\beta_{9} \text { GrossK }+\beta_{10} \text { Mfgxpts }+\beta_{11} \text { NetFDI } \\
& (+) \quad(+) \quad(+)
\end{aligned}
$$

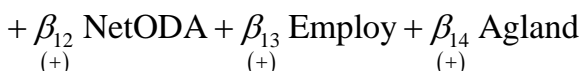

$$
\begin{aligned}
& +\beta_{15} \text { PubHealth }+\beta_{16} \text { Youth } \%+\varepsilon \\
& (+) \quad(-)
\end{aligned}
$$

where PPPGNI = Purchasing Power Parity GNI per capita, in dollars in 2009.

Death $=$ Number of battle-related deaths in civil wars, 2000-2008.

Homicides $=$ Intentional homicide rate per 100,000 people, for the latest year that data are available, 2000-
2009.

AsylumRef $=$ Number of refugees hosted by a country as at the end of 2009.

OriginRef $=$ Number of refugees originating from each country at the end of 2009.

MilExp = Military expenditure as a percentage of GDP, in 2009.

YouthMale $=$ Percentage of male youth population 15 to 34 years old, in 2009.

Literacy = Adult literacy rate, in 2008.

AgValue = Agriculture value added per worker, measured in 2000 dollars, 2005-2007.

GrossK = Gross capital formation as a percentage of GDP, in 2009.

Mfgxpts = Manufactured exports as a percentage of total exports, in 2009.

NetFDI $=$ Foreign direct investment net inflows, in millions of dollars, in 2009.

NetODA $=$ Net official development assistance per capita, in dollars, in 2008.

Employ = Proportion of a country's population that is employed, in 2008.

Agland = Share of land that is arable under permanent crops and pastures, in 2008.

PubHealth $=$ Public health expenditure as a percent of total health expenditure, in 2009.

Youth\% = Percentage of youth population 15 to 34 years old, in 2009.

From a theoretical standpoint, civil wars adversely affect per capita income by cutting down the labor force. To capture this effect we use the number of battle-related deaths in civil wars as well as the intentional homicide rate per 100,000 people and expect the coefficient estimate for both these variables to have a negative sign.

Per capita income is also adversely affected when neighboring countries end up hosting refugees who have been displaced when the latter had to leave their homes and thus became a burden for hosting countries. On the other hand, civil wars also cause natives to seek asylum elsewhere and in the process reduce the size of the labor force. We thus expect that the coefficient estimate on both these variables to have a negative sign.

The effect of military expenditures on per capita GNI may be ambiguous. On one hand, as government expenditures from productive social overhead capital such as roads, schools, and bridges are rechanneled to less productive defense spending, leading to a decline in per capita GNI. However, if military expenditures bring about more citizen security and foster investment in both human and physical capital, the effect would be an improvement in the level of per capita output.

Generally speaking, a developing country with a high percentage of its population being young usually has a 
lower per capita level of income because labor productivity due to the acquisition of skills and the accumulation of human capital tends to vary positively with a worker's age. As a result, we expect the coefficient estimate on this variable to have a negative sign. On the other hand, the effect of the male youth population on per capita GDP (or GNI) may be ambiguous since in developing countries young males tend to participate in the labor force at an early age and hence contribute positively to output but at the same time may be a source of militants and thus engage in activities that may lead to a lower level of per capita income such as joining gangs that may go around extorting businesses or destroying private property.

To capture the effect of human capital on per capita GDP we use two variables: the adult literacy rate and the share of public health expenditures in total health expenditures. We expect that both these variables will make a positive impact on the level of per capita income.

Since agriculture still plays an important role in terms of value added as a percentage of GDP in developing countries, we choose to include two variables to capture the contribution of this sector to the economy: the agricultural value added per worker and the share of total land area that is arable under permanent crops and permanent pastures. We expect that these two variables will exert a positive influence on per capita GDP in a developing country, all else being equal.

Ideally, we would have liked to use the physical capital stock as regressor since this is an input used to produce aggregate output. Unfortunately, data on this variable is not readily available. As a result, we choose to include gross capital formation as a percentage of GDP instead. Since labor is another input used in the aggregate production function, we use the proportion of a country's population that is employed as another explanatory variable and expect that this variable and gross capital formation to have a positive impact on the level of per capita GDP.

Since it is often the case that developing countries experience shortages of loanable funds due to their low saving-to-income ratio, they often need to look beyond their borders in search of these funds. We thus choose to include foreign direct investment (FDI) net inflows and per capita net official development assistance (ODA) to capture the effect of these external sources of funding on per capita GDP. We expect that the coefficient estimate on both these variables to have a positive sign ${ }^{2}$.

${ }^{2}$ It is worth noting that Burnside and Dollar find that foreign aid has a positive effect on growth in developing countries with good fiscal, monetary, and trade policies while having little effect when poor policies are present. Our study, rather than looks at the effect of aid on growth, focuses on its effect on the development, as measured by per capita GDP [7].
Finally, in order to capture the externality effects of exports on output in terms of more efficient use of resources, scale economies, and labor training and "demonstration effects", we add the share of manufactures in total exports as input in the aggregate production function and expect that this variable will exert a positive impact on per capita GDP. Data for all variables are from the 2011 World Development Report and the 2011 World Development Indicators [5,6].

\section{Empirical Results}

Table 1 gives least-squares estimates of regression coefficients in Equation (1) for a sample of thirty-eight developing countries. The goodness of fit of the model to the data is very good as indicated by the value of 0.742 of the adjusted coefficient of determination. We observe that only six explanatory variables are significant, the coefficient estimates of two of which do not have the anticipated sign, namely the intentional homicide rate and net official development assistance per capita. As the number of refugees hosted by a developing country increases by 1000 , we would expect a one-dollar decrease in purchasing power parity gross national income per capita, other things being equal. On the other hand,

Table 1. Empirical results (full model).

\begin{tabular}{ccc}
\hline & Coefficient Estimate & t-Statistic \\
\hline Intercept & 5148.467 & 1.008 \\
Battle & -0.038 & -1.094 \\
Homicides & 41.792 & $1.846^{* *}$ \\
AsylumRef & -0.001 & $-1.714^{* *}$ \\
OriginRef & -0.001 & -0.233 \\
MilExp & 530.200 & $2.186^{* *}$ \\
YouthMale & 282.923 & 0.607 \\
Literacy & 16.688 & 1.275 \\
AgValue & 0.718 & $2.570^{*}$ \\
GrossK & 15.031 & 0.549 \\
Mfgxpts & 11.698 & 1.339 \\
NetFDI & 0.017 & 0.865 \\
NetODA & -20.470 & $-3.464^{*}$ \\
Employ & -14.228 & -0.517 \\
Agland & -9.250 & -0.930 \\
PubHealth & 41.659 & $3.016^{*}$ \\
Youth\% & -293.839 & -1.154 \\
\hline
\end{tabular}

Adjusted $\mathrm{R}^{2}=0.742 .{ }^{*}$ Significant at the 1 percent level. ${ }^{* *}$ Significant at the 5 percent level. 
the positive sign of the coefficient estimate for the share of military expenditures in the GDP variable suggests that these expenditures bring about a better sense of security for the citizens and hence result in a higher level of per capita GNI. All else equal, a one-percentage point increase in military expenditures' share in GDP is expected to lead to an increase of $\$ 530$ in per capita purchasing power parity gross national income. Regression results also show that a one-hundred-dollar increase in the agriculture value added per worker is expected to bring about a $\$ 72$ increase in per capita GNI, ceteris paribus. In addition, as the share of public health expenditures in total health expenditures increases by one percentage point, we would expect per capita GDP to increase by about $\$ 42$, all else being equal.

Using the backward elimination stepwise method we arrive at a revised model, the regression results of which are reported in Table 2 . We note that the goodness of fit of the model to the data is better as indicated by the higher value of 0.775 of the adjusted coefficient of determination. We observe that all but five variables are statistically significant at the 5 percent level or lower.

We note that the intentional homicide rate variable continues to have the unexpected positive sign. The impact of military expenditures as a percentage of GDP on per capita GDP has been reduced to $\$ 468$ for every percentage point increase in the value of this variable, while that of the number of refugees hosted by the developing country remains unchanged. The adult literacy rate variable is now statistically significant at the 5 percent level. All else equal, a one-percent increase in this rate is ex-

Table 2. Empirical results (revised model).

\begin{tabular}{ccc} 
& Coefficient Estimate & t-Statistic \\
Intercept & 3214.267 & 0.954 \\
Homicides & 29.727 & 1.600 \\
AsylumRef & -0.001 & $-1.786^{* *}$ \\
MilExp & 468.183 & $2.289^{* *}$ \\
Literacy & 22.036 & $2.180^{* *}$ \\
AgValue & 0.907 & $4.809^{*}$ \\
Mfgxpts & 11.597 & 1.666 \\
NetFDI & 0.023 & 1.620 \\
NetODA & -17.088 & $-3.530^{*}$ \\
Agland & -11.418 & -1.301 \\
PubHealth & 47.762 & $4.076^{*}$ \\
Youth\% & -138.242 & -1.541 \\
\hline
\end{tabular}

Adjusted $\mathrm{R}^{2}=0.775$. ${ }^{*}$ Significant at the 1 percent level. ${ }^{* *}$ Significant at the 5 percent level. pected to lead to a $\$ 22$ dollar increase in per capita GDP. We also observe that there is a slight increase in the effect of agriculture value added per worker (from about $\$ 72$ to $\$ 91$ for every one hundred dollar increase) on per capita GDP.

The results also show that the share of manufactures in total merchandise exports is now very close to be statistically significant at the 5 percent level and its coefficient estimate does have the expected positive sign. Its removal from the statistical model leads to a decrease in the value of the adjusted coefficient of determination. All else equal, a one-percentage point increase in the value of this variable is expected to result in an increase of $\$ 12$ in per capita GDP. Similarly, the foreign direct investment net inflow variable is now significant, while its coefficient estimate also has the expected positive sign. A one-hundred-million dollar increase in foreign direct investment net inflow is expected to lead to an increase of about \$2 in per capita GDP, ceteris paribus. The effect of the share of public health expenditures in total health expenditures on per capita GDP also increases slightly from about $\$ 42$ to $\$ 48$ for every one percentage point increase in the value of this variable, holding all other variables constant. Finally, the share of youth 15 to 34 years old in the total population variable is now significant since its removal also leads to a decrease in the value of the adjusted coefficient of determination. We also observe that its coefficient estimate does have the expected negative sign. All else equal, a one-percentage point increase in the proportion of the total population that are 15 to 34 years old is expected to lead to a decrease of about \$138 in per capita GDP.

The fact that we obtain statistical results that seem to be inconsistent with our hypothesis about the impact of the intentional homicide rate, net official development assistance per capita, and the share of arable land in the total land area variables on per capita income growth could be due to a simultaneity bias or the extent of the multicollinearity among explanatory variables. The extent of the latter problem is reported by the sample correlation coefficient matrix on Table 3 . This undoubtedly makes the interpretation of the coefficient estimates on these variables more difficult.

\section{Conclusions}

In this paper we use a statistical model and data from a sample of thirty-eight developing economies to empirically analyze the impact of security and other explanatory variables on the level of per capita GDP. From the statistical results we are able to draw the following conclusions:

1) Within the set of developing economies in this 
Table 3. Sample correlation coefficient matrix.

\begin{tabular}{|c|c|c|c|c|c|c|c|c|c|c|}
\hline & Homicides & AsylumRef & MilExp & Literacy & AgValue & NetFDI & NetODA & PubHealth & Agland & Youth\% \\
\hline Homicides & 1 & & & & & & & & & \\
\hline \multirow[t]{2}{*}{ AsylumRef } & -0.105 & 1 & & & & & & & & \\
\hline & -0.633 & & & & & & & & & \\
\hline \multirow[t]{2}{*}{ MilExp } & -0.264 & 0.326 & 1 & & & & & & & \\
\hline & -1.646 & 2.066 & & & & & & & & \\
\hline \multirow[t]{2}{*}{ Literacy } & 0.121 & -0.170 & 0.214 & 1 & & & & & & \\
\hline & 0.733 & -1.034 & 1.315 & & & & & & & \\
\hline \multirow[t]{2}{*}{ AgValue } & 0.246 & 0.107 & 0.367 & 0.339 & 1 & & & & & \\
\hline & 1.523 & 0.648 & 2.368 & 2.163 & & & & & & \\
\hline \multirow[t]{2}{*}{ NetFDI } & -0.144 & 0.092 & 0.052 & 0.106 & -0.145 & 1 & & & & \\
\hline & -0.871 & 0.552 & 0.314 & 0.639 & -0.877 & & & & & \\
\hline \multirow[t]{2}{*}{ NetODA } & 0.004 & -0.232 & 0.319 & 0.090 & 0.134 & -0.282 & 1 & & & \\
\hline & 0.025 & -1.430 & 2.020 & 0.539 & 0.810 & -1.763 & & & & \\
\hline \multirow[t]{2}{*}{ PubHealth } & 0.107 & -0.228 & -0.168 & 0.110 & -0.003 & -0.011 & 0.191 & 1 & & \\
\hline & 0.646 & -1.408 & -1.024 & 0.663 & -0.017 & -0.069 & 1.165 & & & \\
\hline \multirow[t]{2}{*}{ Agland } & 0.074 & -0.073 & -0.172 & 0.100 & 0.125 & 0.045 & -0.001 & -0.017 & 1 & \\
\hline & 0.445 & -0.440 & -1.048 & 0.606 & 0.757 & 0.269 & -0.008 & -0.099 & & \\
\hline \multirow[t]{2}{*}{ Youth\% } & -0.084 & 0.104 & -0.201 & -0.026 & 0.213 & -0.253 & 0.027 & 0.115 & 0.057 & 1 \\
\hline & -0.506 & 0.628 & -1.234 & -0.157 & 1.310 & -1.569 & 0.161 & 0.692 & 0.344 & \\
\hline
\end{tabular}

Note: Bold t-statistics imply statistical significance at the 10 percent or lower level.

study, citizen security does play a vital role in fostering economic development. Governments in these countries need to devise program aimed at lowering the intentional homicide rate while ensuring that their military expendi- tures are used to provide more security for their citizens.

2) The international community needs to play an active role in helping countries avoid conflict including civil wars so as to minimize the number of refugees that are hosted by developing countries since refugee inflows have the tendency of draining a government's resources, while at the same time increasing population growth, which may lead to a reduction in per capita income.

3) Governments in developing countries need to increase the level of human capital by investing in education to improve the adult literacy rate and by playing a more active role in providing their citizens with an adequate level of health status. Efforts should also be aimed at increasing labor productivity in agriculture as well as enlarging areas of arable land relative to the total land mass.

4) Governments in these countries also need to solicit foreign direct investment and encourage a larger share of manufactures in total merchandise exports. In addition, programs aimed at controlling population growth through family planning may result in a lower dependency ratio and thus bring about more economic development.

\section{Acknowledgements}

I would like to thank Thi Minh Chi Le for her support during the completion of this paper.

\section{References}

[1] J. C. Murdoch, and T. Sandler, "Civil Wars and Economic Growth: Spatial Dispersion,” American Journal of Political Science, Vol. 48, No. 1, 2004, pp. 138-151. doi:10.1111/j.0092-5853.2004.00061.x

[2] R. Bayer and M. Rupert, "Effects of Civil Wars on International Trade,” Journal of Peace Research, Vol. 41, No. 6, 2004, pp. 699-713. doi:10.1177/0022343304047433

[3] K. Gaibulloev and T. Sandler, "Growth Consequences of Terrorism in Europe,” Kyklos, Vol. 61, No. 3, 2008, pp. 411-424. doi:10.1111/j.1467-6435.2008.00409.x

[4] O. De Groot, "The Spillover Effects of Conflict on Economic Growth in Neighboring Countries in Africa,” Defence and Peace Economics, Vol. 21, No. 2, 2010, pp. 149-164. 
[5] World Bank, "World Development Report 2011: Conflict, Security and Development," Oxford University Press, New York, 2011.

[6] World Bank, "World Development Indicators 2011,"
Oxford University Press, New York, 2011.

[7] C. Burnside and D. Dollar, "Aid, Policies, and Growth," American Economic Review, Vol. 90, No. 4, 2000, pp. 847-868. doi:10.1257/aer.90.4.847 